\title{
DYNAMIC MODEL FOR ENERGY PREDICTING IN WECS
}

\author{
Delfín Silió Salcines, Julio Largo Cabrerizo, Carlos Renedo Estébanez and Severiano Pérez Remesal \\ Department of Electrical Engineering, \\ E.T.S.I.I. y T., Cantabria University \\ Avda. Los Castros s/n, 39005 Santander (Spain) \\ Phone: +34 942 201370, fax: +34 942 201385, e-mail: siliod@unican.es, largoj@unican.es, renedoc@unican.es, \\ severiano.perez@unican.es
}

\begin{abstract}
This paper presents a dynamic simulation model of a wind generator, that allow to predict the quantity of removable energy in a specific place, using as initial condition wind measurements register in that place. The model is composed of four modules. The frist one is used to model de wind behaviour. The second is orientend to the aerodynamics model. The third is focused on the mechanical connection between the hub and the electrical machine. Finally, the fourth is dedicated to the electrical machine.

The first model dedicated to the wind behaviour, includes an stochastic model. The aerodynamics conversion is base on the Strip Theory. The connection between the hub and the electrical machine used the mechanical differential equations. Finally, the electrical machine is modelled using the Power System Blockset including in Matlab Simulink.
\end{abstract}

\section{Key words}

Wind turbine, induction generator, wind energy, dynamic model.

\section{Introduction}

The success of wind power as an alternate source of energy is a direct function of the economics of designing and manufacturing the wind machine. One of the most important aspects of the design is the development of performance prediction methods. It is the purpose of this study to present analytical procedure for evaluating the energy extracted of a horizontal-axis wind turbines.

The whole model comprises a wind speed model and wind turbine models, as follows:

- The wind speed model outputs the wind speeds for the wind turbine, taking into account the tower shadow of the 3-bladed turbine.

- The individual wind turbine model includes electrical, mechanical and aerodynamic submodels:

- the aerodynamic submodel is a standard $C P$ based model, extended with dynamicstall effects.
- the mechanical submodel describes the dynamics of the drive train.

- the electrical submodel consists of an induction generator, a soft-starter, a capacitor bank for reactive power compensation and a step-up transformer.

\section{Model description}

The proposed structure of the wind generator consists of a wind turbine and squirrel cage induction generator and three-phase R-L network connected as shown in Fig.1.

\section{A. The wind speed model}

The wind speed model used in this work has a structure that is similar to that proposed in [1]. It is assumed that the wind speed consists of the sum of two components, namely:

- $\bar{U}$ average value of the wind speed

$-v(t)$ wind speed turbulence.

This model is of course independent of the characteristics of the wind turbine itself and can therefore be applied in combination with all wind turbine models. The wind speed $V(t)$ is thus given by the following equation:

$V(t)=\bar{U}+v(t)$

where the initial average value of the wind speed $\bar{U}$ is a constant value and $v(t)$ is time dependent.

The second component of the wind speed model represents the wind speed turbulence.Turbulence is described by a power spectral density. In this paper, the following spectral density is used 


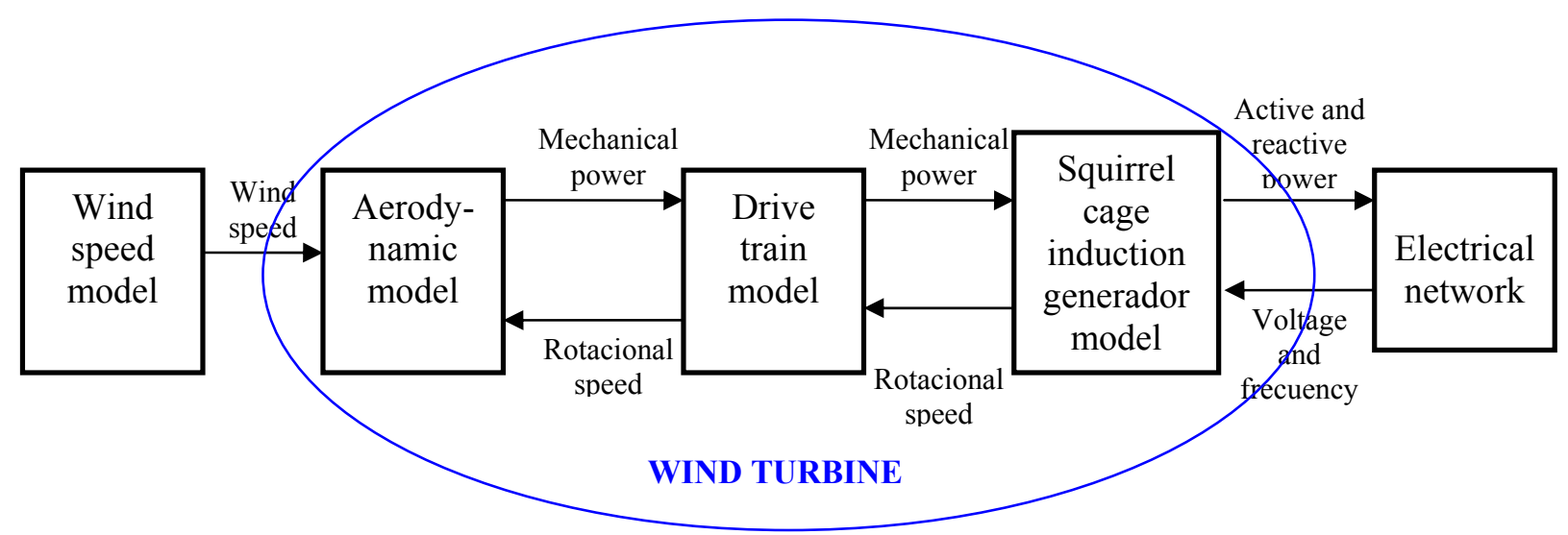

Fig. 1. General structure of constant speed wind turbine model

$$
\frac{n \cdot S_{v}(n)}{\sigma^{2}}=\frac{\left(n \frac{z}{\bar{U}}\right)}{f_{m}\left(1+\frac{1,5}{f_{m}}\left(n \frac{z}{\bar{U}}\right)\right)^{5 / 3}}
$$

where $S_{v}(n)$ is the spectral density, $n$ is frequency [Hz], $z$ is the height at which the wind speed signal is occurs, which is equal to the wind turbine hub height [m], $f_{m}=$ 0,06 is a constant value and $\sigma$ is the turbulence intensity give by the equation

$$
\sigma=\bar{U} \cdot I_{v}(z)=\bar{U} \cdot \frac{1}{\ln \left(z / z_{0}\right)}
$$

where $I_{v}(z)$ is the turbulence intensity and $z_{0}$ is the roughness length. In Fig. 2 shown a tridimensional power spectral density given by (2)

The parameter $z_{0}$ is used to characterise the landscape type around the turbine, as it reflects the impact of the structure of the wind turbine surroundings on the turbulence intensity.

TABLE I.- Roughness length $z_{0}$ for various landscape types

\begin{tabular}{|l|c|}
\hline Landscape type & $\begin{array}{l}\text { Roughness } \\
\text { length } \mathbf{z}_{\mathbf{0}}[\mathbf{m}]\end{array}$ \\
\hline Opend sea, Sand & $1 \mathrm{e}^{-4}-1 \mathrm{e}^{-3}$ \\
\hline Snow surface & $1 \mathrm{e}^{-3}-5 \mathrm{e}^{-3}$ \\
\hline Mown grass, Steppe & $1 \mathrm{e}^{-3}-1 \mathrm{e}^{-2}$ \\
\hline Long grass, Rocky ground & $0,004-0,1$ \\
\hline Forest, Cities, Hilly areas & $1-5$ \\
\hline
\end{tabular}

A method to generate a time series from a given power spectral density is necessary to this end. Here, the method described in [1] is used, which is also applied in [2]. This method is based on the summation of a great number of sine functions with different frequencies, of which the amplitude is determined by the given power spectral density, from which the time series is to be derived.

A power spectral density only contains information on the amplitude of the various frequency components of the signal, but no information on the phase angle. In the time domain, however, both the amplitude and the phase angle of the sine components of a signal must be known. Therefore, to derive a time series from a given power spectral density, the phase angle of each of the frequency components must be established. In the applied method, this is done by randomizing the initial phase angle of each of the frequency components that are included in the time series in the interval from 0 to $2 \pi$. Thus, an infinite amount of random time series corresponds to a single power spectral density.

The following equation applies to the turbulence component of the wind speed sequence

$$
v(t)=\sqrt{2} \sum_{k=1}^{m}\left[S\left(n_{k}\right) \Delta n\right]^{1 / 2} \cdot \cos \left(2 \pi n_{k} t+\beta_{k}\right)
$$

where $n_{k}$ is the $\mathrm{k}^{\text {th }}$ frequency component, $\Delta n$ is the frecuency spacing and $\beta_{k}$ is the random phase, uniformly distibuted in $(0,2 \pi)$. In Fig. 3 shown wind under turbulent conditions according (4).

\section{B. Aerodynamic model}

In this section, the purpose is to model the velocity field immediately behind a wind turbine rotor. This is achieved by combining diferent basic aerodynamic theories applied to wind turbines. First momentum theory together with blade element theory are used to derive expressions for the forces on a ideal rotor, divided into consecutive annulus. Later the obtained expressions are adjusted to include tip losses and cases when the turbine is heavily loaded. Finally, these equations are modified in order to work for wind turbines operating at an angle to the wind, yaw. 

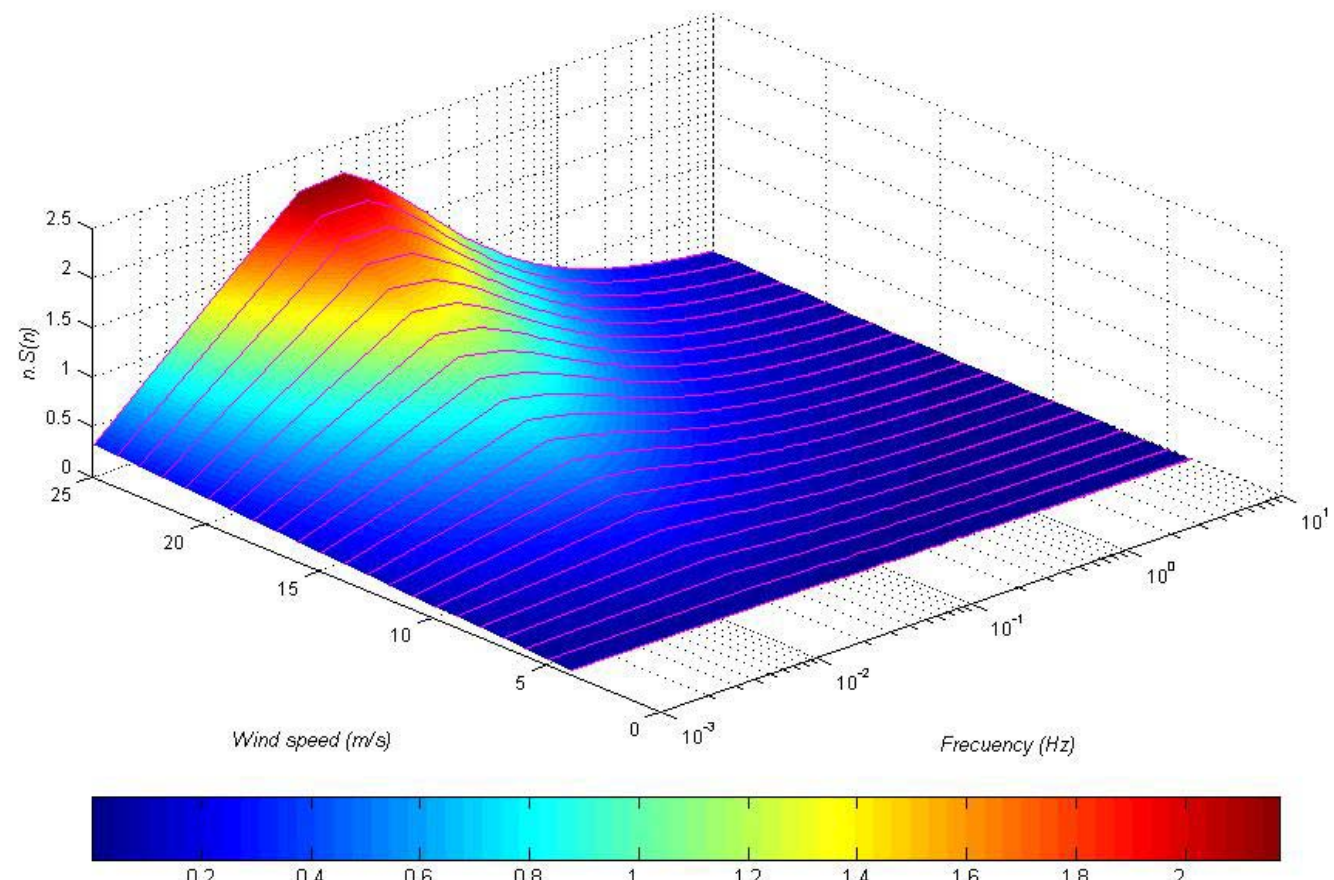

Fig. 2. Tridimensional power spectral density of Ernst-Cathor. $\left(z=50 \mathrm{~m}, z_{0}=0.02 \mathrm{~m}\right)$

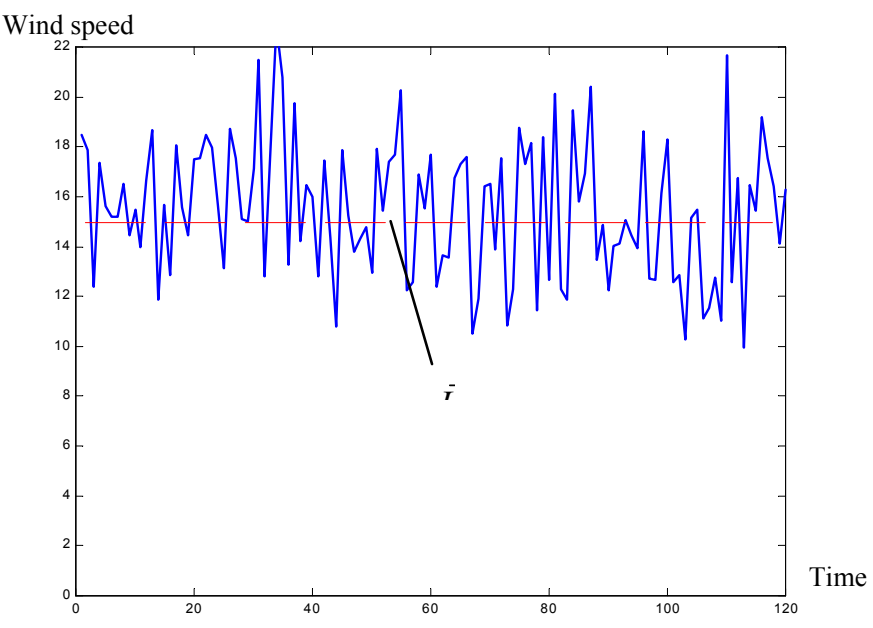

Fig. 3. Wind under turbulent conditions

$$
\left(\bar{U}=15 \mathrm{~m} / \mathrm{s}, z=50 \mathrm{~m}, I_{v}=0,18\right) \text {. }
$$

By equating the force and torque expressions derived from momentum theory and blade element theory, the following expressions can be derived, which have to be solved iteratively.

$a f(1-a f)=\frac{N c R}{4 \pi\left(R^{2}-R_{r}^{2}\right)} \int_{R_{r}}^{R} \frac{W^{2}}{U_{a}^{2}}\left(C_{L} \cos \phi+C_{D} \sin \phi\right) \frac{d r}{R}$

$a^{\prime} f(1-a f)=\frac{N c R^{3}}{2 \pi\left(R^{4}-R_{r}^{4}\right)} \frac{\left.U_{a}\right)}{\Omega R} \int_{R_{r}}^{R} \frac{W^{2}}{U_{a}^{2}}\left(C_{L} \cos \phi-C_{D} \sin \phi\right) \frac{r}{R} \frac{d r}{R}$

where $a$ is the induction factor and $a^{\prime}$ the tangential interference factor. The resulting velocity acting with an angle $\phi$ to the plane of rotation at the blade is denoted $W$. $\Omega$ is the angular velocity of the blade with cord $c$ (see Figs. 4 and 5). $C_{\mathrm{D}}$ and $C_{\mathrm{L}}$ is the drag and lift coefficient, respectively. $R$ is the radius of the blade and $r$ is the actual radial distance. $N$ is number of blades. Since $a$ and $a$ ' are defined as the values when the blade has passed a given point of the disk, the averaged induction factors at that point, over the course of one revolution will be af and $a^{\prime} f$, respectively, where $f$ is called the tip loss factor. In the analysis used in deriving the above expressions the values of $a$ and $a$ ' were assumed to be constant at each radial distance. This is only true if the pitch and chord vary along the blade in a special way. This is not the case for the airfoil used, but the approach described above can still be used, if we apply the momentum theory to separated annular rings (Fig. 4). Each ring of the disk has a thickness $\mathrm{d} r$ and radius $r$. The momentum theory is applied for each ring separately.

The value of $f$ can be determined has to be determined using an approximate solution derived by Prandtl, or a more complex solution by Goldstein. Both methods, however, gives similar results. Since the Prandtl method is simple closed, but the Goldstein solution is represented by an infinite series of modified Bessel functions, the Prandtl solution is used here.

$$
f(r)=\frac{2}{\pi} \arccos \left[\mathrm{e}^{-\pi s / d}\right]
$$

where $s$ is the distance from the tip, and $d$ is the pitch between the disks, which is taken as being the distance normal to successive helical sheets. 

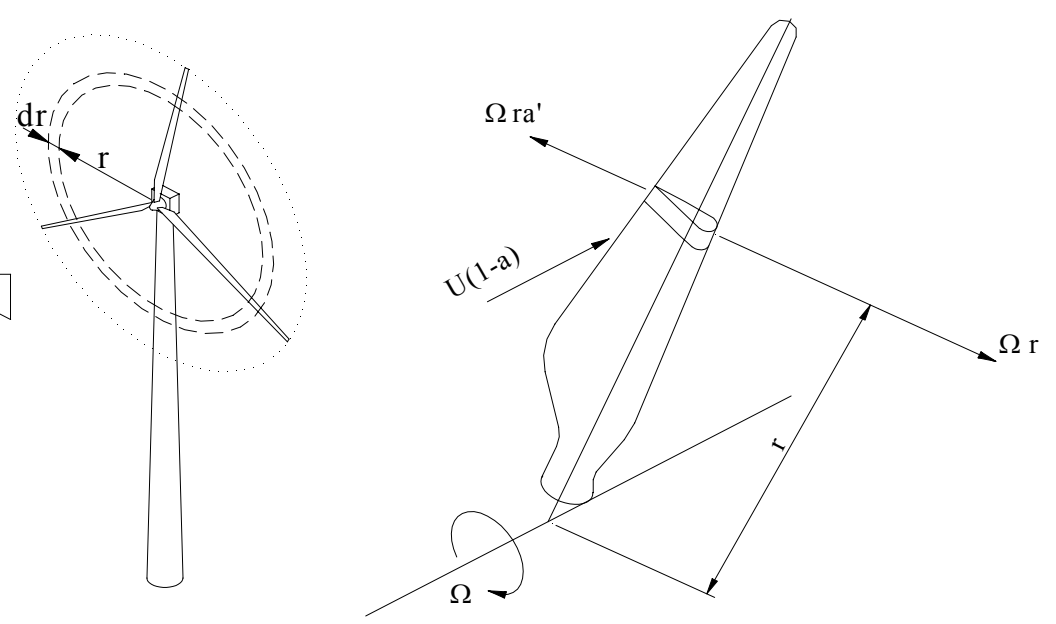

Fig. 4. Blade element swepps out and annulae ring.

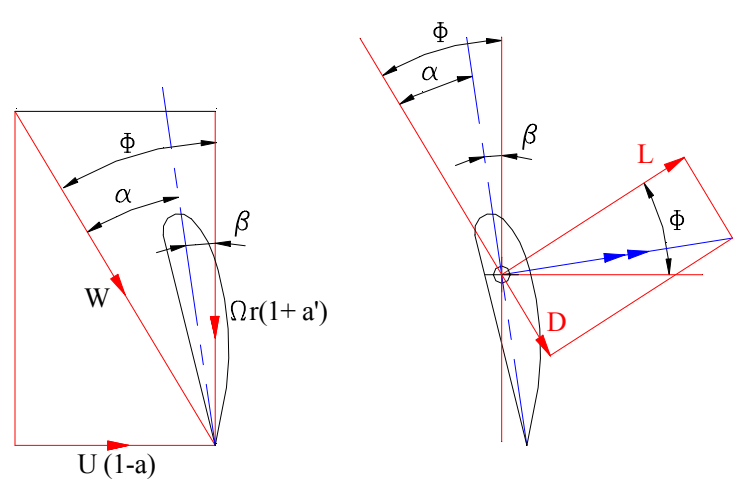

Fig. 5. Velocities and forces acting on a blade element.

\section{Drive train model}

The aerodynamic torque, in a wind turbine, varies all the time due to wind turbulence. The variations however are not directly transferred to the electrical power output because of the dynamic mechanical transmission system. The electrical generators run in a relatively high speed compared to the aerodynamic rotor. The drive train connects high speed in the electrical generator side and slow speed in the aerodynamic rotor using a gearbox. The drive train includes a gearbox; shafts and disc brakes that can be positioned in the low or in the high-speed shaft depending on the size of the wind turbine. On small wind turbines the brakes are positioned in the low speed shaft that reduces the stresses on the gear box during shut down of wind turbines, on large wind turbines, however, the torques in low speed shaft are very high hence the disc brakes are located in the high speed shaft. Figure 6 illustrates the drive train of a wind turbine.

Fig. 7 presents a simplified dynamic drive train model where the gearbox is considered ideal. $T_{\text {aerodyn }}$ is the aerodynamic torque computed from the aerodynamic module, $\omega_{\text {rotor }}$ is the rotational speed of the aerodynamic rotor, $\omega_{\text {generator }}$ is the rotational speed of the induction generator, $T_{\text {electromechanical }}$ is the electromechanical torque in the induction generator, $J_{\text {rotor }}$ is the inertia of the aerodynamic rotor, $J_{\text {generator }}$ is the inertia of the induction generator, $K$ is the equivalent stiffness of the shaft, $D$ is the equivalent damping coefficient.

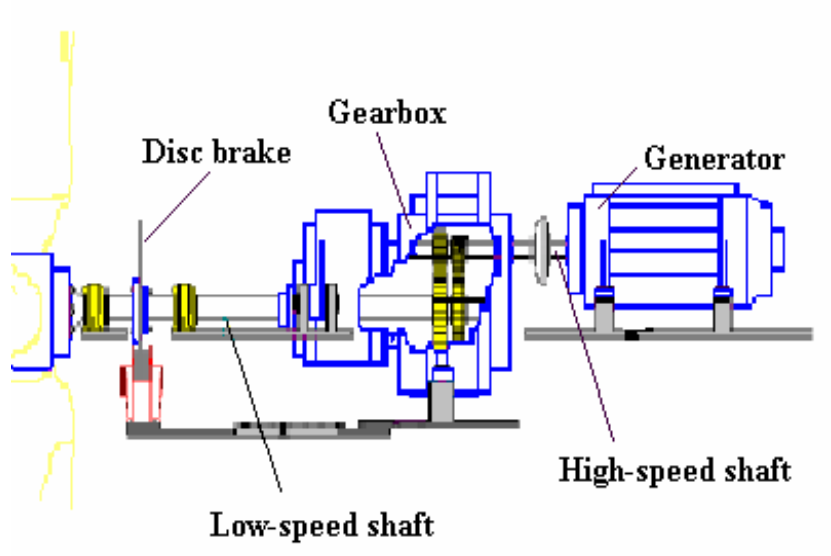

Fig. 6. Drive-train components.

The equations of motion in to the dynamic drive train in Figure 7 can be expressed according to:

$$
\begin{aligned}
& J_{\text {rotor }} \frac{d\left(\omega_{\text {rotor }}\right)}{d t}=T_{\text {aerodyn }}-T_{\text {rotor }} \\
& J_{\text {mec }} \frac{d\left(\omega_{\text {mec }}\right)}{d t}=T_{\text {mec }}-K\left(\delta_{\text {mec }}-\delta_{\text {generator }}\right)- \\
& -D\left(\omega_{\text {mec }}-\omega_{\text {generator }}\right)-T_{\text {generator }} \\
& J_{\text {generator }} \frac{d\left(\omega_{\text {generator }}\right)}{d t}=T_{\text {generator }}-T_{\text {electromechanical }}
\end{aligned}
$$




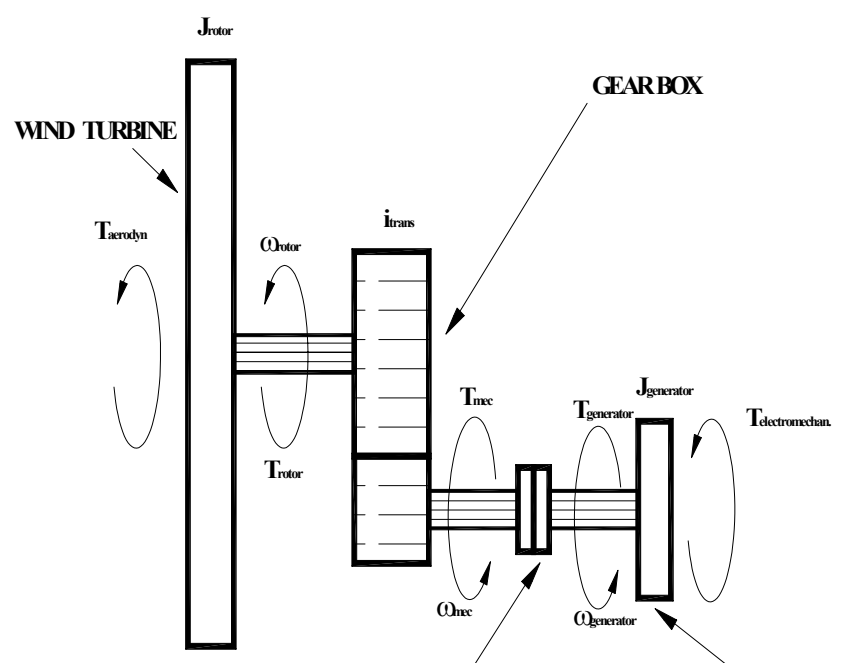

FLEXIBLECOUPUNG(K,D)

GENERATOR

Fig. 7. Dynamic representation of the drive train model.

\section{Squirrel cage induction generator model}

The following equations describe a squirrel cage induction generator in the $d-q$ reference frame [3]. The generator convention is applied, which means that rotor and stator currents are positive when they are outputs

$$
\begin{aligned}
& u_{S d}=-R_{S} i_{S d}+\frac{d}{d t} \psi_{S d}-\omega_{1} \psi_{S q} \\
& u_{R d}=0=-R_{R} i_{R d}+\frac{d}{d t} \psi_{R d}-\left(\omega_{1}-\omega\right) \psi_{R q} \\
& u_{S q}=-R_{S} i_{S q}+\frac{d}{d t} \psi_{S q}+\omega_{1} \psi_{S d} \\
& u_{R q}=0=-R_{R} i_{R q}+\frac{d}{d t} \psi_{R q}+\left(\omega_{1}-\omega\right) \psi_{R d}
\end{aligned}
$$

with $u$ the voltage, $R$ the resistance, $i$ the current, $\omega_{1}$ the stator electrical frequency, $\psi$ the flux linkage and $s$ the rotor slip. The indices $d$ and $q$ indicate the direct and quadrature axis components and $s$ and $r$ indicate stator and rotor quantities.

The $\mathrm{d}-\mathrm{q}$ reference frame is rotating at the synchronous speed with the q-axis leading the d-axis by $90^{\circ}$. The position of the $d$-axis coincides with the maximum of the stator flux, which means that vqs equals the terminal voltage et and vds equals zero. The flux linkages in can be calculated using the following set of equations:

$$
\begin{aligned}
& \psi_{S d}=-L_{S} i_{S d}-L_{m} i_{R d} \\
& \psi_{S q}=-L_{S} i_{S q}-L_{m} i_{R q} \\
& \psi_{R d}=-L_{R} i_{R d}-L_{m} i_{S d}
\end{aligned}
$$

$$
\psi_{R q}=-L_{R} i_{R q}-L_{m} i_{S q}
$$

The equations for the electromechanical torque $T_{\text {electromechanical }}$ and active power $P$ generated or consumed by a squirrel cage induction generator are the following:

$$
\begin{aligned}
& T_{e}=\frac{3}{2}\left(\psi_{S d} i_{S q}-\psi_{S q} i_{S d}\right) \\
& P_{e}=\frac{3}{2}\left(u_{S d} i_{S d}+u_{S q} i_{S q}\right)
\end{aligned}
$$

\section{Simulation result}

In this section, the responses of the models to a particular wind speed sequence is investigated. The simulation results presented here were obtained with MATLAB ${ }^{\circledR}$.

In Figs. 8-10, are depicted wind speed sequence, the simulated rotor speed and the output power, respectively, for the wind turbine simulated. The characteristics of the wind turbine are given in table II. The generator parameters of the induction generator used in the constant speed wind turbine are given in table III.

TABLE II.- Characteristics of simulated wind turbine.

\begin{tabular}{|l|c|}
\hline \multicolumn{1}{|c|}{ WIND TURBINE CHARACTERISTIC } & VALUE \\
\hline Rotor speed & $25,5 \mathrm{RPM}$ \\
\hline Rotor diameter & $46 \mathrm{~m}$ \\
\hline Rotor swept area & $1662 \mathrm{~m} 2$ \\
\hline Number of blades & 3 \\
\hline Nominal power & $660 \mathrm{KW}$ \\
\hline Nominal wind speed & $15 \mathrm{~m} / \mathrm{s}$ \\
\hline Gear box ratio & $1: 59,5$ \\
\hline Inertia & $550.10^{3} \mathrm{kgm}{ }^{2}$ \\
\hline Inertia constant & $2,82 \mathrm{~s}$ \\
\hline Shaft stiffness & 0,3 p.u. $/ \mathrm{el} . \mathrm{rad}$. \\
\hline
\end{tabular}

TABLE III.- Induction generator parameters

\begin{tabular}{|l|c|}
\hline \multicolumn{1}{|c|}{ GENERATOR CHARACTERISTIC } & VALUE \\
\hline Number of poles & 4 \\
\hline Voltaje & $690 \mathrm{~V}$ \\
\hline Generator speed & 1517 RPM \\
\hline Mutual inductance $\mathrm{L}_{\mathrm{m}}$ & 3,0 p.u. \\
\hline Stator leakage inductance $\mathrm{L}_{\mathrm{S}}$ & 0,10 p.u. \\
\hline Rotor leakage inductance $\mathrm{L}_{\mathrm{R}}$ & 0,08 p.u. \\
\hline Stator resistance $\mathrm{R}_{\mathrm{s}}$ & 0,01 p.u. \\
\hline Rotor resistance $\mathrm{R}_{\mathrm{r}}$ & 0,01 p.u. \\
\hline Compensating capacitor & 0,5 p.u. \\
\hline Inertia constant & $0,15 \mathrm{~s}$ \\
\hline
\end{tabular}




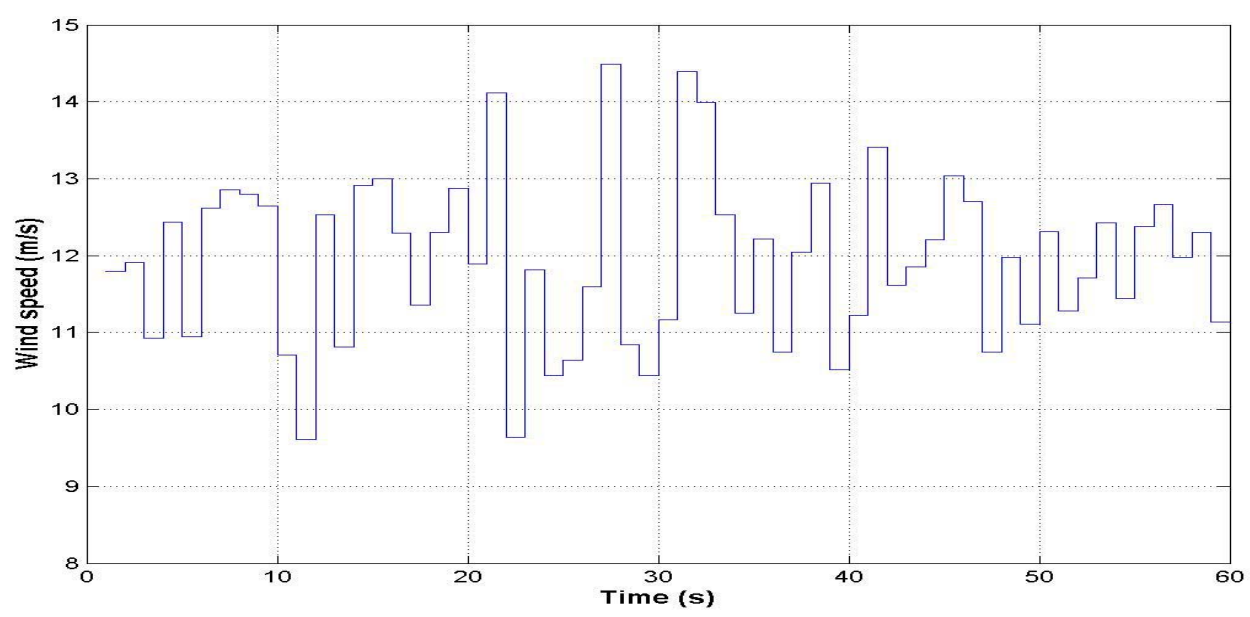

Fig. 8. Wind speed simulated $\left(\bar{U}=12 \mathrm{~m} / \mathrm{s}, I_{v}=0,2\right)$.

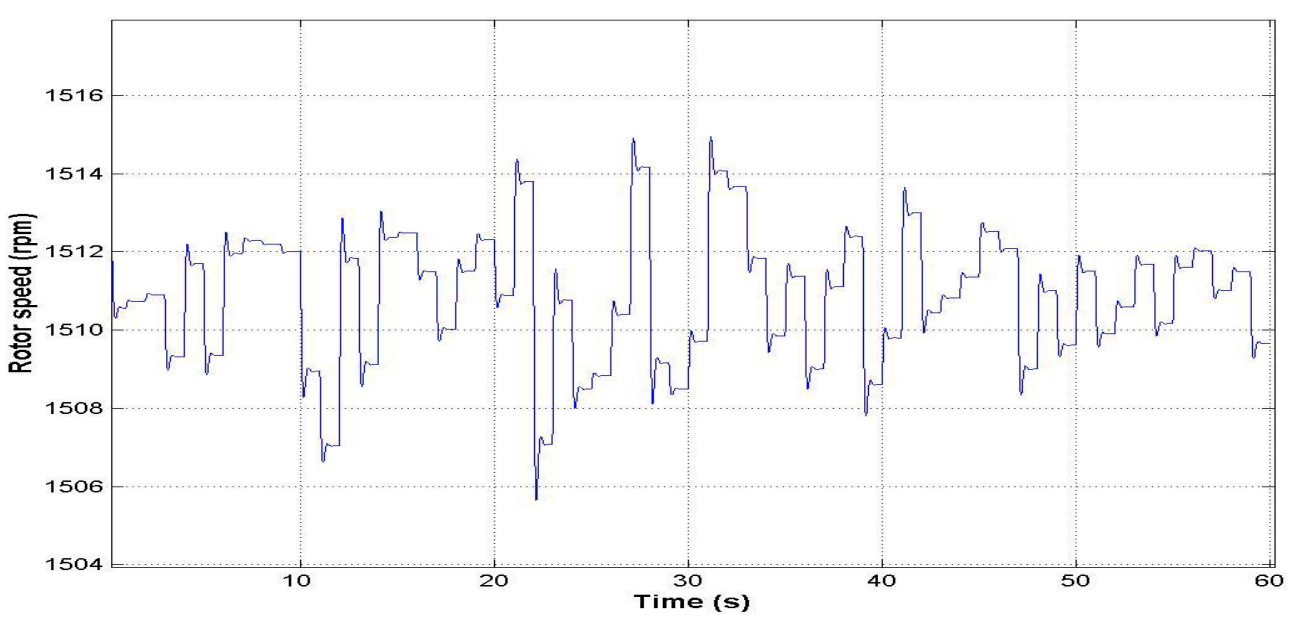

Fig. 9. Rotor speed (rpm)

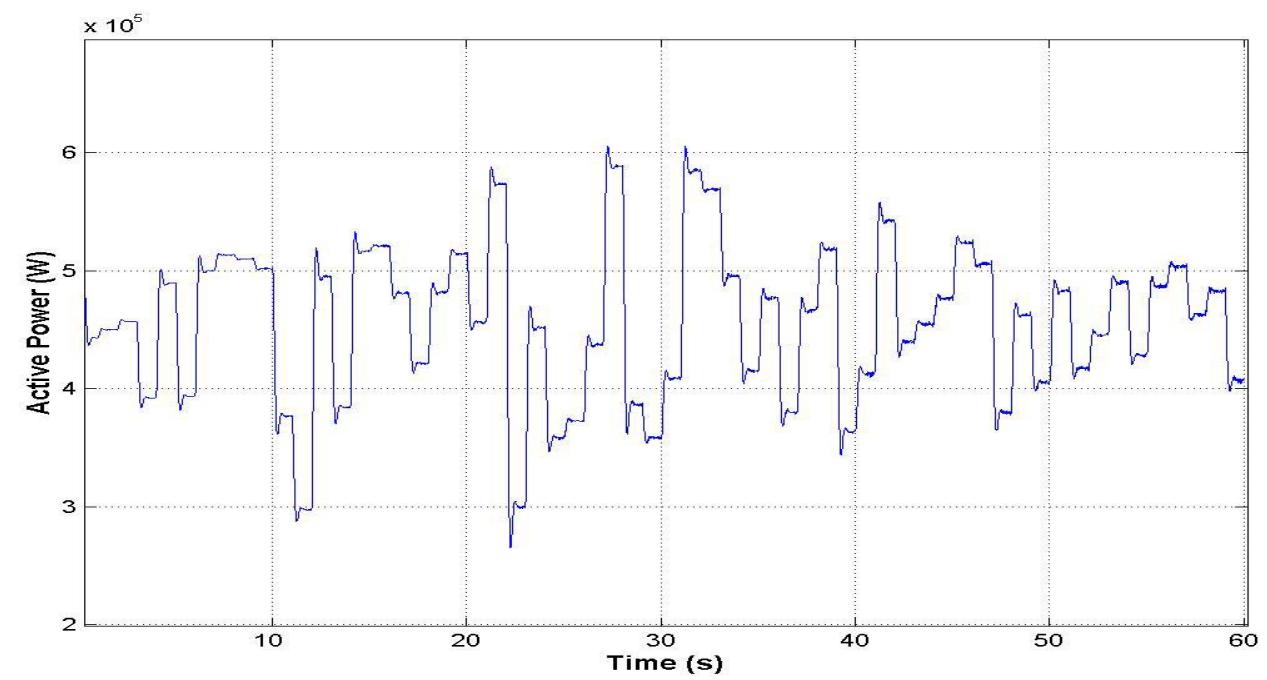

Fig. 10. Active power (W) 


\section{Conclusions}

A simulation model for a type of wind generator based on an asynchronous generator interconnected to the electric network has been developed. A wind speed time serie is used as input to a numerical model of the turbine; thus we determined a wind power time serie.

This model is expected to give realistic and correct results when used for different system performance studies. It is expected that as experience and additional hard test data is obtained, this model will continue to evolve, in terms of parameter values and structure.

\section{References}

[1] M. Shinozuka, C.M. Jan, "Digital simulation of random processes and its applications", Journal of Sound and Vibration, v.25, n.1, 1972.

[2] O. Wasynczuk, D.T. Man, J.P. Sullivan, "Dynamic behavior of a class of wind turbine generators during random wind fluctuations", IEEE Transactions on Power Apparatus and Systems, v.100, n.6, June 1981.

[3] P. Kundur, Power system stability and control, New York: McGraw-Hill, Inc., 1994. 